\title{
METODE NUMERIK STEPEST DESCENT DENGAN DIRECTION DAN NORMRERATA ARITMATIKA
}

\author{
Rukmono Budi Utomo \\ Universitas Muhammadiyah Tangerang \\ Email: rukmono.budi.u@mail.ugm.ac.id
}

\begin{abstract}
This research is investigating of Steepest Descent numerical method with direction and norm arithmetic mean. This research is begin with try to understand what Steepest Descent Numerical is and its algorithm. After that, we constructing the new Steepest Descent numerical method using another direction and norm called arithmetic mean. This paper also containing numerical counting examples using both of these methods and analyze them self.
\end{abstract}

Keywords: Steepest Descent Methods, Gradient, Direction, Norm Arithmetic Mean

\section{PENDAHULUAN}

Tidak selamanya solusi analitik dari suatu permasalahan matematika khususnya masalah optimisasi dapat dengan mudah ditemukan. Terkadang ditemukan kendala yang cukup rumit sehingga solusi analitik dari permasalahan optimisasi tersebut tidak mudah ditemukan. Berdasarkan hal tersebut solusi numerik merupakan sesuatu hasil yang cukup baik untuk dicari meski hasilnya merupakan hampiran atau pendekatan. Metode numerik merupakan suatu metode pendekatan (approximation) dari solusi sejati, dan berdasarkan hal tersebut terdapat besarnya angka kesalahan (eror) yang dihasilkan oleh perhitungan numerik. Kesalahan ini lebih sering diakibatkan baik karena pemotongan suku atau pembulatan nilai (Rinaldi, 2008). Masalah optimisasi merupakan persoalan yang banyak menggunakan metode numerik dalam mencari solusi penyelesaian tatkala solusi analitik sulit ditemukan.

Menurut kendalanya (constrain), masalah optimisasi dibagi dua yakni masalah optimisasi dengan kendala dan tanpa kendala, sedangkan menurut variabel bebasnya masalah optimisasi juga dibagi atas dua, yakni masah optimisasi dengan satu variabel bebas dan banyak variabel bebas.Masalah optimisasi juga dibagi atas dua bagian berdasarkan banyaknya fungsi objektif yang dioptimalkan, yakni masalah optimisasi dengan satu fungsi objektif dan banyak fungsi objektif.

Metode numerik untuk menyelesaikan masalah optmisasi dengan kendala dapat menggunakan metode Kuhn-Tucker atau pengali Lagrange, sedangkan untuk masalah optimisasi tanpa kendala dengan satu variabel bebas dapat menggunakan metode Golden Rasio, Fibonacci, Biseksi, Dichotomus dan Secant. Lebih lanjut untuk menyelesaikan masalah optmisasi dengan lebih dari satu variabel bebas dapat menggunakan metode Aksial, Newton, Hook and Jeeves, Stepest Descent, Arah Konjugasi, dan Rosenberg (Bazaraa, 2006). Untuk menyelesaikan masalah optimisasi dengan banyak fungsi objektif dapat menggunakan program linear multi objektif, namun hal tersebut tidak dibahas dalam tulisan ini

$$
\text { Makalah ini membahas }
$$

mengenai metode numerik Steepest Descent dengan arah pencarian 
(direction)dan keputusan berhenti (norm) berupa rerata aritmatika. Makalah Metode numerik Stepest Descent dengan rerata aritmatika sebenarnya sudah dibahas oleh penulis dan dibawakan pada seminar nasional matematika UM malang, namun pada makalah tersebut keputusan berhenti iterasi (norm) masih menggunakan $\left\|\nabla Z\left(X_{k}\right)\right\|<\varepsilon, k=1,2, \ldots \quad$ Dalam tulisan kali ini bentuk keputusan berhenti suatu iterasi (norm) juga merupakan rerata aritmatika atau dengan kata lain

$$
\left\|\frac{\sum_{k=1}^{k} \nabla Z\left(X_{k}\right)}{k}\right\|<\varepsilon, k=1,2, \ldots
$$

Diketahui bahwa metode Steepest Descent pada umumnya menggunakan arah pencarian gradien biasa $d_{k}=-\nabla Z\left(X_{k}\right)$, sedangkan pada penelitian ini arah pencarian dimodifikasi menjadi rerata aritmatika $d_{k}=\frac{-\sum_{k=1}^{k} \nabla Z\left(X_{k}\right)}{k}$. Tidak hanya arah pencarian (direction) yang berupa rereta aritmatika, namun keputusan berhenti satu iterasi mestinya juga berupa rerata aritmatika. Berdasarkan hal tersebut dalam tulisan ini didefinisika norm

$$
\left\|\frac{\sum_{k=1}^{k} \nabla Z\left(X_{k}\right)}{k}\right\|<\varepsilon, k=1,2, \ldots \text {. }
$$

Penelitian dilakukan dengan memahami terlebih dahulu mengenai metode numerik Steepest Descent dengan arah pencarian gradien biasa kemudian menyusunalgoritma untuk metode Steepest Descent dengan arah pencariandirection dan keputusan berhentinormrerata aritmatika Dalam tulisan ini juga akan diberikan contoh perhitungan numerik untuk metode Steepest Descent dengan kedua arah pencarian tersebut beserta analisis dan perbandingan keakuratan solusi antara keduanya.

\section{KAJIAN TEORI}

Definisi Ruang Vektor (Anton, 1991)

Himpunan tak kosong $V$ merupakan ruang vektor apabila $\forall x, y, z \in V$ dan $a, b \in R$ sedemikian hingga memenuhi aksioma-aksioma sebagai berikut:

$$
\begin{aligned}
\text { i. } & x+y \in V \\
\text { ii. } & x+y=y+x \\
\text { iii. } & (x+y)+z=x+(y+z) \\
\text { iv. } & \exists 0 \in V \quad \text { sehingga } \\
& 0+V=V+0=0 \quad \exists-x \in V \text { sehingga } x+(-x)=0 \\
\text { v. } & \exists \text { vi. } \\
\text { vii. } & a(x+y)=a x+a y \\
\text { viii. } & (a+b) x=a x+b x \\
\text { ix. } & (a b) x=a(b x) \\
x . & 1 x=x
\end{aligned}
$$

\section{Definisi Norm (Anton, 1991)}

Diberikan $X, Y$ dua vektor. Sembarang bilangan riil $\|X\|$ dinamakan norm dari $X$ apabila memenuhi aksioma-aksioma sebagai berikut

$$
\begin{array}{cl}
\text { i. } & \mid X \| \leq 0 \\
\text { ii. } & \mid a X \|=0 \leftrightarrow X=0 \\
\text { iii. } & \|a X\|=\mid a\|X\|, a \in R \\
\text { iv. } & \mid X+Y\|\leq\| X\|+\| Y \|
\end{array}
$$

Definisi Ruang Bagian (Anton, 1991) Himpunan bagian $W$ dari $V$ disebut ruang bagian dari $V$ jika $W$ ruang vektor dengan operasi jumlah dan kali sama seperti

\section{Definisi Kombinasi Linear (Anton, 1991)}

Misalkan $X_{i}, 1 \leq i \leq m$ vektor-vektor di $V$ maka $X$ disebut kombinasi linear dari vektor-vektor $X_{i}$ jika $X=\sum_{i=1}^{m} a_{i} X_{i}$ 
Definisi Bebas Linear (Anton, 1991)

Vektor $X_{i}, \quad 1 \leq i \leq m$ anggota-anggota $V$ disebut tak bebas linear jika dan hanya jika terhadap bilangan-bilangan riil tak semuanya nol sedemikian hingga

$\sum_{i=1}^{m} a_{i} X_{i}=0 . \quad$ Apabila pembuat nol hanya $a_{i}=0$, maka vektor-vektor tersebut dikatakan bebas linear.

\section{Definisi Basis Ortonormal (Salmah, 2011)}

Basis ortonormal di $\square^{2}$ didefinisikan sebagai $\quad l_{1}=(1,0)^{T}$ dan $l_{2}=(0,1)^{T}$, sedangkan untuk $\square^{n}$ basis ortonormal didefinisikan dengan $l_{1}=(1,0, \ldots, 0)^{T}, l_{2}=(0,1, \ldots, 0)^{T}, \ldots, l_{n}=(0,0, \ldots, 1)^{T}$

Definisi Hubungan Dua Vektor (Salmah, 2011)

Diberikan dua buah vektor $X, Y$ dengan $X=\left\{x_{1}, x_{2}, \ldots, x_{n}\right\}$ dan

$Y=\left\{y_{1}, y_{2}, \ldots, y_{n}\right\}$. Pernyataan berikut dapat dibuktikan benar

i. $X=Y$ jika dan hanya jika

$$
x_{i}=y_{i} \forall i, i=1,2, \ldots, n
$$

ii. $X<Y$ jika dan hanya jika

$$
x_{i}<y_{i} \forall i, i=1,2, \ldots, n
$$

iii. $X>Y$ jika dan hanya jika

$$
x_{i}>y_{i} \forall i, i=1,2, \ldots, n
$$

Definisi Bola Terbuka (Salmah, 2011)

Diberikan $\quad x_{0} \in \square^{n} \quad$ serta $\rho>0$.

Himpunan

$$
B\left(x_{0}, \rho\right)=\left\{x \in \square^{n}\left\|x_{0}-x\right\|<\rho\right\}
$$

merupakan persekitaran $\rho$ dari $x_{0}$ atau disebut bola terbuka dengan pusat $x_{0}$ dan radius $\rho$.
Definisi Titik Dalam (Salmah, 2011)

Titik $x_{0} \in X \subseteq \square^{n}$ disebut titik dalam (interior point) dari himpunan $X$ jika $\exists \delta>0$ sehingga $B\left(x_{0}, \delta\right) \subseteq X$

\section{Definisi Titik Batas (salmah, 2011)}

Titik $x_{0} \in X \subseteq \square^{n}$ disebut titik batas (boundary point) dari himpunan $X$ jika setiap sekitar $\rho$ dari $x_{0}$ memuat beberapa titik yang berada di $X$ dan beberapa titik yang tidak berada di $X$

Definisi Himpunan Terbuka(Salmah, 2011)

Himpunan $X$ disebut himpunan terbuka jika setiap titik dari $X$ merupakan titik dalam dari $X$. Lebih lanjut himpunan $Y$ merupakan himpunan tertutup jika komplemen dari himpunan terbuka.

Definisi Himpunan Tertutup(Salmah, 2011)

Himpunan $X$ disebut himpunan tertutup jika himpunan tersebut memuat semua titik batasnya.

Definisi Bentuk Kuadratik (Chong, 2001)

$$
\begin{aligned}
& F(X)=c_{11} x_{1}^{2}+c_{2} 2 x_{2}^{2}+\ldots+c_{n n} x_{n}^{2}+c_{12} x_{1} x_{2} \\
& +c_{1,3} x_{1} x_{3}+\ldots+c_{23} x_{2} x_{3}+\ldots
\end{aligned}
$$

dengan $c_{i j} \in R, 1 \leq i, \quad j \leq n \quad$ disebut fungsi bentuk kuadratik dengan $n$ variabel bebas $x_{1}, x_{2}, \ldots, x_{n}$

Definisi Fungsi Definit (Chong, 2001)

Bentuk kuadratik $X^{T} A X$ disebut positif (negatif) definit jika $X^{T} A X>(<) 0$ untuk semua $X \neq 0$ dan terdapat sekurangnya satu vektor tak nol sedemikian hingga $X^{T} A X=0$. Apabila tidak memenuhi keduanya, maka bentuk kuadratik tersebut dikatakan indefinite

Teorema Fungsi Definit (Chong, 2001)

Suatu matriks $A$ dikatakan 
a. Positif definit jika dan hanya jika $\lambda_{i}>0$

b. Negatif definit jika dan hanya jika $\lambda_{i}<0$

c. Positif semi definit jika dan hanya jika $\lambda_{i}<0$

d. Negatif semi definit jika dan hanya jika $\lambda_{i} \leq 0$

dengan $\lambda_{i}$ merupakan nilai-nilai eigen dari matriks $A$ dan ketidaksamaan dicapai untuk sekurang-kurangnya satu $j$. Lebih lanjut apabila $\lambda_{i}$ tidak memenuhi i,ii,iii,iv maka matriks $A$ disebut indefinite

Definisi Minimum Global (Chong, 2001)

Fungsi $\quad F(x)$ dikatakan memiliki minimum global di $x_{0}$ dalam $S$ jika $f(x) \geq f\left(x_{0}\right)$

\section{Definisi Minimum Lokal Relatif (Chong, 2001)}

Fungsi $\quad F(x)$ dikatakan memiliki

minimum lokal di $x_{0}$ dalam $S$ jika terdapat sekitar $\delta$ dari $x_{0}$ sehingga $f(x) \geq f\left(x_{0}\right)$ untuk setiap $x$ di dalam persekitaran tersebut.

\section{Definisi Deret Taylor (Sawaragi, 1985)}

Deret Taylor untuk fungsi $F(X)$ dengan $X=\left\{x_{1}, x_{2}, \ldots, x_{n}\right\}$ didefinisikan sebagai

$F(X+\Delta x)=F(X)+\nabla F(X) \Delta X+\frac{(\Delta X)^{\prime}}{2} H(X)(\Delta x)+\vartheta_{3}$

dengan $\vartheta_{3}$ merupakan suku berderajat besar, dan $H(X)$ merupakan metrik Hessian yang didefinisikan sebagai

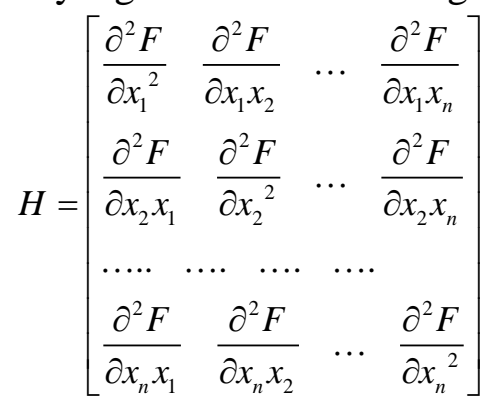

Syarat perlu agar $X$ merupakan titik ekstrim dari fungsi $F(X)$ adalah $\nabla F(X)=0 \quad$ dengan $\nabla F(X)=\left(\frac{\partial F}{\partial x_{1}}, \frac{\partial F}{\partial x_{2}}, \ldots, \frac{\partial F}{\partial x_{n}}\right)$

\section{Algoritma Stepest Descent} (Bazaraa,2006)

Diberikan $Z=F(X)=F\left(x_{2}, x_{2}, ., x_{n}\right)$ dan akan ditentukan nilai $X=\left\{x_{1}, x_{2}, ., x_{n}\right\}$ yang meminimalkan fungsi $F(X)$ tersebut

i. Ambil $X_{1}=\left\{x_{1}, x_{2}, . ., x_{n}\right\} \in R^{n}$ yang merupakan sembarang titik awal dan ò $>0$ yang merupakan suatu konstanta positif yang menyatakan besarnya kesalahan eror yang ditoleransi.

ii. Dibentuk fungsi gradient $\nabla Z(X)=\left[\frac{\partial Z}{\partial x_{1}}, \frac{\partial Z}{\partial x_{2}}, \ldots, \frac{\partial Z}{\partial x_{n}}\right]$ dan tentukan $\nabla Z\left(X_{1}\right)$ dan lakukan untuk $\nabla Z\left(X_{k}\right)$

iii. Apabila $\left\|\nabla Z\left(X_{k}\right)\right\|<\varepsilon$, maka iterasi berhenti, sebaliknya iterasi dilanjutkan

iv. Tentukan $\lambda_{k}$ dengan cara mencari titik ekstrim $Z\left(X_{k}+\lambda_{k} d_{k}\right)$ yakni dengan cara menderivatifkan fungsi $Z\left(X_{k}+\lambda_{k} d_{k}\right)$ dan menyamadengankan nol dengan arah pencarian $d_{k}=-\nabla Z\left(X_{k}\right)$

v. Nilai $X_{k}$ ditentukan dengan $X_{k}=X_{k-1}+\lambda_{k-1} d_{k-1}$

\section{METODE PENELITIAN}

Metode untuk melakukan penelitian ini adalah studi literatur, yakni dengan membaca dan memahami konsep teori metode numerik untuk menyelesaikan 
masalah optimisasi khususnya Stepest Descent. Buku yang digunakan untuk melakukan penelitian ini antara lain buku-buku seperti, An Introduction to Optimization karya Edwin K.P.Chong dan Stanislaw $\mathrm{H}$ Zak, Theory of Multiobjective Optimization karya Yoshikazu Sawaragi, Hirotaka Nakayama dan Tetsuzo Tanino, Nonlinear Programming Theory and Algorithm karya Mochtar S Bazaraa, Hanif D Sherali dan C.M Shetty, Metode Numerik karya Rinaldi Munir, Diktat kuliah Optimisasi karya Salmah, Prosiding Rukmono pada semnas UM yang berjudul Metode Numerik Stepest Descent dengan Arah Pencaraian Rerata Aritmatika dan materi kuliah metode numerik program studi pendidikan matematika UMT yang penulis tulis sendiri.

Setelah memahami metode numerik Stepest Descent dengan arah pencarian gradien $d_{k}=-\nabla Z\left(X_{k}\right)$ dikembangkan metode numerikStepest Descent dengan arah pencarian rerata aritmatika dan didefinisikan dengan $\quad d_{k}=\frac{-\sum_{k=1}^{k} \nabla Z\left(X_{k}\right)}{k}$ dengan

norm

$$
\left\|\frac{\sum_{k=1}^{k} \nabla Z\left(X_{k}\right)}{k}\right\|<\varepsilon, k=1,2, \ldots \text {. }
$$

Terakhir dilakukan simulasi perhitungan mencari solusi numerik dari masalah optimisasi dua variabel dengan cara metode numerik Stepest Descent dengan arah pencarian gradient biasa dengan rerata aritmatika beserta analisis perhitungannya.

\section{HASIL PENELITIAN DAN PEMBAHASAN}

Berdasarkan algoritma Stepest Descent dngan arah pencarian gradien $d_{k}=-\nabla Z\left(X_{k}\right)$, akan dikembangkan suatu metode Stepest Descent dengan arah pencarian rerata aritmatika.

Algoritma Stepest Descent Dengan Arah Pencaraian Rerata Aritmatika Diberikan fungsi $Z=F(X)=F\left(x_{2}, x_{2}, ., x_{n}\right)$ dan akan ditentukan $\quad X=\left\{x_{1}, x_{2}, ., x_{n}\right\}$ yang meminimalkan fungsi $F(X)$ tersebut $\}$

i. Ambil $X_{1}=\left\{x_{1}, x_{2}, ., x_{n}\right\} \in R^{n}$ titik sembarang titik awal dan ò $>0$ suatu konstanta positif yang menyatakan besarnya kesalahan eror yang ditolerasnsi.

ii. Dibentuk

$\nabla Z(X)=\left[\frac{\partial Z}{\partial x_{1}}, \frac{\partial Z}{\partial x_{2}}, \ldots, \frac{\partial Z}{\partial x_{n}}\right]$

kemudian tentukan untuk $\nabla Z\left(X_{1}\right)$ serta $\nabla Z\left(X_{k}\right)$

iii. Apabila $\left\|\nabla Z\left(X_{k}\right)\right\|<\varepsilon$, maka iterasi berhenti, sebaliknya iterasi dilanjutkan

iv. Cari $\lambda_{k}$ dengan cara mencari titik ekstrim $Z\left(X_{k}+\lambda_{k} d_{k}\right)$ yakni dengan cara menderivatifkan $Z\left(X_{k}+\lambda_{k} d_{k}\right)$ dan menyamadengankan nol serta arah pencarian direction $d_{k}=\frac{-\sum_{k=1}^{k} \nabla Z\left(X_{k}\right)}{k}$ dan

keputusan

berhenti iterasi norm

$\left\|\frac{\sum_{k=1}^{k} \nabla Z\left(X_{k}\right)}{k}\right\|<\varepsilon, k=1,2, \ldots$

v. Apabila nilai $X_{k+1}=X_{k}$, maka hal ini disebut Rounding atau berputar putar, sehingga tidak mungkin dilakukan iterasi selanjutnya. Berdasarkan hal tersebut, perhitungan harus dihentikan dan diambil kesimpulan bahwa nilai numerik 
dari suatu masalah optimisasi tanpa kendala adalah $X_{k}$ atau $X_{k+1}$. Nilai hampiran ini dapat berupa nilai analitik atau memang hanya berupa nilai pendekatan.

\section{Contoh Numerik 1 (Rukmono, 2016)}

Tentukan nilai $X=\left\{x_{1}, x_{2}\right\} \quad$ yang meminimalkan

$Z\left(x_{1}, x_{2}\right)=2 x_{1}^{2}+x_{2}^{2}-3 x_{1}-x_{2} \quad$ dengan menggunakan metode Stepest Descent dengan toleransi kesalahan ò $=0.03$

Solusi Stepest Descent dengan Arah Pencarian Gradien

Ambil sebarang titk awal $X_{1}=\left\{-1, \frac{1}{2}\right\} \in R^{2}$. Berdasarkan masalah optimisasi di atas dapat ditentukan $\nabla Z\left(X_{1}\right)=[-7,0]$.Karena norm $\left\|\nabla Z\left(X_{1}\right)\right\|=7>\varepsilon \quad$ maka iterasi dilanjutkan dengan arah pencarian $d_{1}=-\nabla Z\left(X_{1}\right)=[7,0]$ dan berdasarkan hal tersebut dapat diperoleh $\lambda_{1}=\frac{1}{4}$.

Apabila dicari lebih lanjut, akandiperoleh nilai $X_{2}=\left\{\frac{3}{4}, \frac{1}{2}\right\}$ dengan nilai gradien $\nabla Z\left(X_{2}\right)=[0,0]$ dan norm $\left\|\nabla Z\left(X_{2}\right)\right\|=0<\varepsilon$. Berdasarkan hal tersebut iterasi berhenti sehingga nilai $X_{2}=\left\{x_{1}, x_{2}\right\}$ yang meminimalkan masalah optimisasi di atas adalah $X_{2}=\left\{\frac{3}{4}, \frac{1}{2}\right\}$.

Karena $\quad\left\|\nabla Z\left(X_{2}\right)\right\|=0<\varepsilon \quad$ hal ini mengindikasikan bahwa solusi numerik ini sama dengan solusi analitiknya. Pada penyelesaian masalah optimisisasi tanpa kendala di atas, terlihat bahwa untuk nilai awal $X_{1}=\left\{-1, \frac{1}{2}\right\} \in R^{2}$ dan arah pencarian $d_{k}=-\nabla Z\left(X_{k}\right)$, solusi numerik yang dihasilkan sama dengan solusi analitik yakni $X=\left\{\frac{3}{4}, \frac{1}{2}\right\}$ dan langkah pengerjaannya hanya menbutuhkan dua iterasi.

Solusi Stepest Descent dengan Arah Pencarian dan Norm Rerata Aritmatika

Tetap diambil sebarang titk awal $X_{1}=\left\{-1, \frac{1}{2}\right\} \in R^{2} . \quad$ Berdasarkan masalah optimisasi di atas dapat ditentukan $\nabla Z\left(X_{1}\right)=[-7,0]$.

Karena $\operatorname{norm}\left\|\nabla Z\left(X_{1}\right)\right\|=7>\varepsilon \quad$ maka iterasi dilanjutkan dengan arah pencarian $d_{1}=-\nabla Z\left(X_{1}\right)=[7,0]$ dan berdasarkan hal tersebut dapat diperoleh $\lambda_{1}=\frac{1}{4}$. Apabila dicari lebih lanjut, akan diperoleh nilai $X_{2}=\left\{\frac{3}{4}, \frac{1}{2}\right\}$ dengan $\left\|\frac{\nabla Z\left(X_{1}\right)+\nabla Z\left(X_{2}\right)}{2}\right\|=7>\varepsilon$

dan dengan arah pencarian rerata sebagai berikut $d_{2}=\frac{-\sum_{k=1}^{2} \nabla Z\left(X_{k}\right)}{k}=-\left[\frac{\nabla Z\left(X_{1}\right)+\nabla Z\left(X_{2}\right)}{2}\right]=\left[\frac{7}{2}, 0\right]$

- Berdaarkan hal tersebut diperoleh $\lambda_{2}=$ o sehingga $\quad X_{3}=\left\{\frac{3}{4}, \frac{1}{2}\right\}=X_{2}$. Perhatikan bahwa nilai $X_{3}=X_{2}=\left\{\frac{3}{4}, \frac{1}{2}\right\}$ , berdasarkan hal tersebut terjadi Rounding sehingga bagaimanapun perhitungan diberhentikan. Berdasarkan hal tersebut nilai numerik diambil $X_{2}=\left\{\frac{3}{4}, \frac{1}{2}\right\} \quad$ yang kebetulan juga merupakan nilai analitiknya. Dengan 
demikian, solusi yang ditemukan dengan metode ini sesuai dengan solusi aslinya.

Contoh Numerik 2 (Rukmono, 2016)

Pandang kembali contoh numerik1. Apabila $\quad \operatorname{diambil} \overline{X_{1}}=\{-1,1\} \in R^{2}$, penyelesaian akan coba dilakukan dengan metode Steepest Descent dengan kedua jenis arah pencarian.

\section{Solusi Stepest Descent dengan Arah Pencarian Gradien}

Berdasarkan hal tersebut diperoleh $\nabla Z\left(X_{1}\right)=[-7,1]$ dengan norm $\left\|\nabla Z\left(X_{1}\right)\right\|=\sqrt{50}>\varepsilon$. Karena norm masih lebih besar dari $\varepsilon$, maka iterasi dilanjutkan. Arah pencarian $d_{1}=-\nabla Z\left(X_{1}\right)=[7,-1]$ dan berdasarkan hal tersebut dapat diperoleh $\lambda_{1}=\frac{50}{198}$. Apabila dicari, diperoleh $X_{2}=\left\{\frac{76}{99}, \frac{74}{99}\right\}$ dengan $\nabla Z\left(X_{2}\right)=[0.070,0.494]$ dan nilai norm $\left\|\nabla Z\left(X_{2}\right)\right\|=0.498>\varepsilon, \quad$ berdasarkan hal tersebut iterasi dilanjutkan. Dengan cara analog, diperoleh $d_{2}=-\nabla Z\left(X_{2}\right)=[-0.070,-0.494]$ sehingga berdasarkan hal tersebut dapat diperoleh $\lambda_{2}=0.49$. Lebih lanjut diperoleh niali $\overline{X_{3}}=\{0.732,0.504\}$ dengan nilai gradien $\nabla Z\left(X_{3}\right)=[-0.072,0.008]$ dan nilainorm adalah $\left\|\nabla Z\left(X_{3}\right)\right\|=0.07>\varepsilon . \quad$ Proses dilanjutkan sehingga diperoleh arah pencarian

$d_{3}=-\nabla Z\left(X_{3}\right)=[0.072,-0.008] \mathrm{dan}$

$\lambda_{3}=0.25$. Berdasarkan hal tersebut diperoleh $X_{4}=\left\{\frac{3}{4}, \frac{1}{2}\right\} \quad$ dengan nilai gradien $\nabla Z\left(\overline{X_{4}}\right)=[0,0]$ dan

$\left\|\nabla Z\left(\overline{X_{4}}\right)\right\|=0<\varepsilon \quad$ sehingga iterasi berhenti dan solusi numeriknya juga merupakan solusi analitik

Solusi Stepest Descent dengan Arah Pencarian dan Norm Rerata Aritmatika

Diambil $\overline{X_{1}}=\{-1,1\} \in R^{2}$ sebarang nilai awal. Berdasarkan hal tersebut diperoleh nilai gradient $\nabla Z\left(X_{1}\right)=[-7,1]$ dengannorm $\left\|\nabla Z\left(X_{1}\right)\right\|=\sqrt{50}>\varepsilon$. Karena norm masih lebih besar dari $\varepsilon$, maka iterasi dilanjutkan. Karena arah pencarian $d_{1}=-\nabla Z\left(X_{1}\right)=[7,-1]$ maka

berdasarkan hal tersebut dapat diperoleh $\lambda_{1}=\frac{50}{198}$. Apabila dicari, maka akandiperoleh $\quad$ nilai $X_{2}=\left\{\frac{76}{99}, \frac{74}{99}\right\}$ dengan nilai gradien $\nabla Z\left(X_{2}\right)=[0.070,0.494]$ dan norm $\left\|\frac{\nabla Z\left(X_{1}\right)+\nabla Z\left(X_{2}\right)}{2}\right\|=3.544>\varepsilon$.

Nilai arah pencarian $d_{2}$ ditentukan dengan

$$
d_{2}=\frac{-\sum_{k=1}^{2} \nabla Z\left(X_{k}\right)}{2}=-\left[\frac{\nabla Z\left(X_{1}\right)+\nabla Z\left(X_{2}\right)}{2}\right]=[3.465,-0.747]
$$

.Berdasarkan hal tersebut diperoleh $\lambda_{2}=0.002538 \quad$ sehingga dapat ditemukan nilai $X_{3}=\{0.7764,0.7455\}$ 
Lebih lanjut $\nabla Z\left(X_{3}\right)=[0.1056,0.4911]$ dengan $\left\|\sum_{i=1}^{3} \nabla Z\left(X_{i}\right)\right\|=2.369>\varepsilon$. Karena norm masih lebih besar dari $\varepsilon$, maka iterasi dilanjutkan. Dengan cara yang sama akan diperoleh $d_{3}=[2.274,-0.6617]$ dengan $\lambda_{3}=0.00039$ sehingga dapat ditemukan $X_{4}=\{0.7853,0.7429\}$ dengan $\nabla Z\left(X_{4}\right)=[0.1412,0.4858]$ dan norm $\left\|\sum_{i=1}^{5} \nabla Z\left(X_{4}\right)\right\|=1.781>\varepsilon . \quad$ Iterasi dilanjutkan sehingga diperoleh $d_{4}=[1.6708,-0.6172] \mathrm{dan}$

$\lambda_{4}=0.0053$. Berdasarkan hal demikian diperoleh nilai $X_{5}=\{0.794,0.739\}$ dengan

$\nabla Z\left(X_{5}\right)=[0.176,0.478]$ dan

$\left\|\nabla Z\left(X_{5}\right)\right\|=1.428>\varepsilon$.

Berdasarkan perhitungan ini terdapat dua hipotesa yang dapat diambil yakni Pertama nilai $x_{1} \in \square^{2}$ semakin menjauhi nilai aslinya yakni $x_{1}=0.75$ namun untuk $x_{2} \in \square^{2}$ terlihat mendekati nilai aslinya yakni $x_{2}=0.5 \in \square^{2}$ dan suatu saat akan berhenti ketika akan tetap berhenti saat $\left\|\frac{\sum_{i=1}^{n} \nabla Z\left(X_{k}\right)}{n}\right\|<\varepsilon$. Keduapada saat nilai $x_{2}$

kemungkianan mencapai 0.5 , iterasi tetap tidak dapat berhenti dikarenakan ada kemungkinan untuk nilai norm $\left\|\frac{\sum_{i=1}^{n} \nabla Z\left(X_{k}\right)}{n}\right\|$ tiba -tiba berbalik lebih

besar dari $\varepsilon$. Hal demikian dapat terjadi karena salah satu bagian dari nilai $\frac{\sum_{i=1}^{n} \nabla Z\left(X_{k}\right)}{n}$ semakin positif atau semakin membesar.

\section{KESIMPULAN DAN SARAN}

Dari penelitian yang telah dilakukan, terdapat beberapa hal yang dapat disimpulkan:

i. Dalam suatu masalah optimisasi dua variabel tanpa kendala dengan nilai awal tertentu $X_{1}$, solusi numerik Stepest Descent dengan arah pencarian negtif gradien biasa akan menghasilkan solusi yang identik dengan solusi analitik pada masalah optimisasi yang dibahas dalam tulisan ini. Begitu pula dengan solusi numerik yang dihasilkan oleh metode Stepest Descent dengan arah pencarian dan norm rerata aritmatika. Solusi yang dihasikan identik dengan solusi asli meskipun hal ini diakibatkan karena Rounding

ii. Solusi masalah optimisasi dengan metode Steepest Descent dengan arah pencarian dan normrerata aritmatika dengan titik awal yang lain menghasilkan salah satu nilai dari $x_{i}, i=1,2$ yang menjauhi nilai aslinya. Untuk metode Steepest Descent dengan arah pencarian $\quad d_{k}=\frac{-\sum_{k=1}^{k} \nabla Z\left(X_{k}\right)}{k}$ menghasilkan nilai $x_{2}$ yang semakin akurat dengan solusi asli namun tidak sama halnya dengan $x_{1}$ yang justru menjauhi nilai aslinya. Meski demikian 
masih perlu diperiksa apakah iterasi benar benar berhenti atau suatu saat nlai norm justru malah berbalik membesar lebih dari nilai $\varepsilon$ Hal demikian dapat terjadi karena salah satu bagian dari nilai $\frac{\sum_{i=1}^{n} \nabla Z\left(X_{k}\right)}{n}$ semakin positif atau semakin membesar

Adapun saran dalam penelitian ini adalah perlu dikonstrusi arah pencarian rerata aritmatika yang pas agar baik nilai $x_{1}$ maupun $x_{2}$ yang dihasilkan dapat menuju pada nilai yang seharusnya, yakni mendekati atau sama dengan solusi asalitiknya dan tidak memiliki kemungkinan menghasilkan nilai norm yang justru akan membesar. Lebih lanjut perlu diselidiki untuk masalah optimisasi yang lain dengan nilai awal $X_{1}$ tertentu agar ditemukan kesimpulan umum mengenai kecepatan iterasi menemukan solusi pada metode numericSteepest Descent dengan arah pencarian gradient biasa dengan gradient dan norm rerata aritmatika.

\section{DAFTAR PUSTAKA}

Anton, Howard. 1991. Aljabar Linier. Penerjemah PanturSilaban. Jakarta: Erlangga

Bazaraa. S. Mochtar. 2006. Nonlinear Programming Theory and Algorithms. London: Willey Interscience

K.P.Chong, $\quad$ Edwin..2001. An IntroductionTo Optimization. USA: John Wiley \& Sons, Inc.

Munir, Rinaldi. 2008. Metode numerik. Bandung:Informatika

Salmah. 2011. Diktat Optimisasi. Yogyakarya: FMIPA UGM
Sawaragi, Yoshikazu. 1985. Theory ofmultiobjective optimization. London: Academic Press Inc.

Utomo, Rukmono. Budi. 2016. MetodeNumerik Stepest Descent Dengan Arah Pencarian Rerata Aritmatika, Prosiding Semnas Matematika UM.

Utomo, Rukmono. Budi. 2016. Materi Ajar Metode Numerik FKIP UMT. http://www.fkipumt.ac.id/downloads diunduh 18 $\underline{\text { Mei } 2016}$ 